\title{
DIAGNOSTIC ACCURACY OF PERFUSION-CT USING PEAK ENHANCEMENT INTENSITY (PEI) IN DETECTING HIGH GRADE PANCREATIC DUCTAL ADENOCARCINOMA.
}

\footnotetext{
1. MBBS, FCPS, FRCP

Fellowship of Intervention Radiology (AKU, Karachi).

Senior Registrar

Allied Hospital, Faisalabad.

2. MBBS

Registrar

Department of Radiology

Madina Teaching Hospital

Faisalabad.

3. MBBS

Medical Officer

Department of Medicine

DHQ Jhang.

4. MBBS

Medical Officer

Department of Pediatric Medicine

Allied Hospital Faisalabad.
}

Correspondence Address:

Dr. Muhammad Ahsan

House No. 8A, Tec Town,

Satyana Road, Faisalabad

ahsanjahangir194@gmail.com

Article received on:

19/11/2018

Accepted for publication: 02/04/2019

\begin{abstract}
Abdul Raouf ${ }^{1}$, Adeela Abid Bukhari², Natasha Arshad ${ }^{3}$, Muhammad Ahsan ${ }^{4}$
ABSTRACT: Perfusion CT (P-CT) is a new imaging technique able to provide qualitative and quantitative information on perfusion parameters of tissues, which have been demonstrated to be correlated with histological markers of angiogenesis. Objectives: To estimate the diagnostic accuracy of CT perfusion using PEI in detecting high grade pancreatic ductal adenocarcinoma keeping histopathology as gold standard. Study Design: Cross sectional study. Setting: Radiology department of Allied Hospital Faisalabad. Period: 6 months after approval from June, 2016 to Nov, 2016. Material and Methods: Permission for research was sought from hospital ethical committee. Patients were collected from OPD \& indoor of Radiology and surgical department of Allied Hospital Faisalabad. Confounding variables were controlled by restriction (by excluding the subjects with history of metastatic disease or chemotherapy). CT-Perfusion examination was performed with the patient in supine position on a 128 slice Optima Multi detector CT scanner. Image guided (CT guided) biopsy was done on all patients and specimen was sent to the hospital pathology lab and histopathology was done by senior pathologist, who kept blinded to perfusion-CT analysis. Results: In this study, out of 100 cases, the diagnostic accuracy of CT perfusion using PEI in detecting high grade pancreatic ductal adenocarcinoma keeping histopathology as gold standard was recorded as 90.59\%, 91.49\%, 92.31\%, 89.58\% and $91 \%$ for sensitivity, specificity, positive predictive value, negative predictive value and accuracy rate. Conclusion: We concluded that diagnostic accuracy of CT perfusion using PEI is higher in detection of high grade pancreatic ductal adenocarcinoma keeping histopathology as gold standard.
\end{abstract}

Key words: $\quad$ Adenocarcinoma, CT Scan, CT Perfusion, Ductal Cancer, Pancreas, PEI, Sensitivity, Specificity.

\section{Article Citation: Raouf A, Bukhari AA, Arshad N, Ahsan M. Diagnostic accuracy of perfusion- CT using Peak Enhancement Intensity (PEI) in detecting high grade pancreatic ductal adenocarcinoma. Professional Med J 2019; 26(11):1829- 1834. DOI: 10.29309/TPMJ/2019.26.11.833}

\section{INTRODUCTION}

Pancreatic cancer is one of the leading causes of mortality after fatal cancer diseases in the world. ${ }^{1}$ According to estimate by an American association, among forty five thousand patients of pancreatic cancer thirty eight thousand will die. ${ }^{2}$ The ductal variety of carcinoma of pancreases is more prevalent, and adenocarcinoma variety of this disease have $1 \mathrm{yr}$ and $5 \mathrm{yr}$ survival after confirmed diagnosis of $<20 \%$ and $5 \%$ respectively. ${ }^{3}$

In last year's expressive development in radiology and imaging technology with the advancement of multi detector computed tomography (MDCT) and magnetic resonance imaging (MRI). A lot of development have been done to access the structure of various lesions and organs systems along with various techniques for analysis of metabolic and functional disturbances. ${ }^{4}$

Multi Detector Computed Tomography (MDCT) is major radiological technique used in the diagnosis of any lesion of pancreatic tissue. ${ }^{1}$ CT perfusion (CTP) has recently aroused the interest of many researchers and further studies have been designed thereafter. ${ }^{4}$ Miles et al. for first time applied this technique in pancreas. ${ }^{5}$ Although combined surgical approach have shown a better and longer survival but a longer follow-up is needed to see the long-term complications of the procedure. Still, the early recurrence of adenocarcinoma after complete or partial 
surgical approach has been reported and further increased morbidity and mortality; so the early and accurate cellular diagnosis of this type of pancreatic cancer is required thus minimizing unnecessary surgical procedures. ${ }^{3}$ CTP provides a noninvasive method to evaluate the variables that provide insight into angiogenesis. ${ }^{6}$ The relationship of tissue attenuation with iodinated contrast agent concentration helps in the measurement of various perfusion parameters in relation with various hemodynamic changes after angiogenesis. ${ }^{3}$ Various enhancement time curves like shape of the curve, time-to-peak, peakenhancement intensity (PEI) or area-under-curve are the qualitative variables while the quantitative variables include blood flow, volume (BV) and permeability surface area. ${ }^{7}$

When comparing the use of PEI and BV for various grades of lesions, studies showed significant difference. Prevalence of high grade ductal adenocarcinoma is $62.5 \%$ considering PEI perfusion CT separated and pointed out high grade lesions showing sensitivity \& specificity of $65 \%$ and $92 \%$, respectively. ${ }^{3}$ Sensitivity and specificity for endoscopic ultrasound guided fine needle cytology is $88.6 \%$ and $99.3 \%$ respectively. ${ }^{8}$

This study is thus being carried out that how accurately CT perfusion can detect high grade pancreatic ductal adenocarcinoma by noninvasive method and by accurate characterization of histologic grade this study will help doctors to opt for targeted treatment and early deaths due to unnecessary surgery can be avoided.

\section{MATERIAL AND METHODS}

This cross sectional (validation) study was conducted in the Radiology department of Allied and DHQ hospital Faisalabad six months after approval from the hospital ethical review committee. Patients including males and females aging between 30 to 65 years who have been diagnosed of irregularly marginated hypoechoic mass lesion in in pancreas on ultrasound were included after informed consent. Pancreatic adenocarcinoma was defined as a tumor that histologically form glands and secrete mucin forming tubular structures or cell cluster. Poorly differentiated lesion with several cytological atypia was taken as a feature of high grade. On perfusion CT, PEl value of $17.8 \mathrm{HU}$ was used as cut-off for diagnosis of high grade pancreatic adenocarcinoma. Sensitivity is defined as an ability of perfusion CT to detectthose who havehigh grade pancreatic adenocarcinoma. Specificity was an ability of perfusion CT to exclude those who don't have high grade pancreatic adenocarcinoma. True-positive the cases that was positive for high grade pancreatic adenocarcinoma on perfusion CT and histopathology. True-negative was the cases that were negative for high grade pancreatic adenocarcinoma on perfusion CT and histopathology. Predictive positive value is the actual chance of having a high grade pancreatic adenocarcinoma if found positive on perfusion CT. Negative predictive value chance of not having high grade pancreatic adenocarcinoma if found negative on perfusion CT. Patients undergoing chemotherapy having presence of respectable tumor at imaging examination including patients who had evidence of metastatic disease with deranged renal function test and allergic to contrast agent were excluded from the study. Sample size of 100 calculated sensitivity \& specificity calculator with sensitivity of $65 \%^{3}$, specificity $92 \%$, prevalence rate $62.5 \%^{3}$ having confidence level of $95 \%{ }^{3}$ including precision rate of $10 \%$ for sensitivity and $8 \%$ for specificity. Sample collection done through non-probability consecutive sampling and patients were collected from OPD \& indoor of Radiology and surgical department of Allied Hospital Faisalabad. Objective of study was explained to every subject who fulfills the criteria \& informed consent was taken. Confounding variables were controlled by restriction (by excluding the subjects with history of metastatic disease or chemotherapy). Data was collected and verified by senior radiologists. CTPerfusion examination was done while keeping the patient in supine position using 128 slice Optima Multi detector CT scanner by general electric. Initially an un-enhanced scan with broad coverage was done through $5 \mathrm{~mm}$ slices thus identifying and pointing out the tumor(s) and the volume under perfusion. Perfusion CT was done with frequent $\mathrm{CT}$ s during and after bolus of iodine contrast agent. Various region of interests (ROI) 
were identified in the tumor area using the axial slice to see various perfusion CT parameters and six smaller ROls within the tumor, 2 in central area and 4 in the non-peripheral area. Qualitative variables were identified after analysis of color maps of the tumor and the Quantitative variables were identified using various CT perfusion parameters. Mean values calculated in the software using various CT measurements were noted.

All the data was analyzed by using SPSS V-17. Mean and standard deviation was calculated for all the quantitative variables like age. Frequency and percentage was calculated for all the qualitative variables like gender and true positive. Outcome variables were calculated using 2x2 table taking histopathology as gold standard.

\section{RESULTS}

One hundred subjects were enrolled to estimate the diagnostic accuracy of CT perfusion using PEI in detecting high grade pancreatic ductal adenocarcinoma keeping histopathology as gold standard. Both the inclusion and exclusion criteria were strictly applied. Age distribution of the patients was done, it is shown in the Table-I. Gender distribution is shown in the Table-II.

Frequency of high grade pancreatic ductal adenocarcinoma was recorded in $53 \%(n=53)$ whereas $47 \% \quad(n=47)$ had no findings of the morbidity (Table-III). Diagnostic accuracy of CT perfusion using PEI in detecting high grade pancreatic ductal adenocarcinoma keeping histopathology as gold standard was recorded as $90.59 \%, 91.49 \%, 92.31 \%, 89.58 \%$ and $91 \%$ for sensitivity, specificity, positive predictive value, negative predictive value and accuracy rate. (Table-IV).

\begin{tabular}{|l|c|c|}
\hline \multicolumn{1}{|c|}{ Age } & No. of Patients & $\%$ \\
\hline $30-45$ & 26 & 26 \\
\hline $46-60$ & 74 & 74 \\
\hline Total & 100 & 100 \\
\hline Mean+SD & \multicolumn{2}{|c|}{$50.15+6.60$} \\
\hline
\end{tabular}

\begin{tabular}{|l|c|c|}
\hline \multicolumn{1}{|c|}{ Gender } & No. of Patients & $\%$ \\
\hline Male & 57 & 57 \\
\hline Female & 43 & 43 \\
\hline Total & 100 & 100 \\
\hline \multicolumn{2}{|r|}{ Table-II. Gender distribution } \\
\hline \begin{tabular}{|l|l|} 
Pancreatic Ductal \\
Adenocarcinoma
\end{tabular} \\
\hline Yes & No. of Patients & $\%$ \\
\hline No & 53 & 53 \\
\hline Total & 47 & 47 \\
\hline
\end{tabular}

Table-III. Frequency of high grade pancreatic ductal adenocarcinoma $(n=100)$

\begin{tabular}{|c|c|c|c|}
\hline \multirow[b]{2}{*}{ P-CT } & \multicolumn{2}{|c|}{ Histopathology } & \multirow[b]{2}{*}{ Total } \\
\hline & $\begin{array}{c}\text { Pancreatic } \\
\text { Carcinoma } \\
\text { (Positive) }\end{array}$ & $\begin{array}{l}\text { Pancreatic } \\
\text { Carcinoma } \\
\text { (Negative) }\end{array}$ & \\
\hline Positive & $\begin{array}{c}\text { True } \\
\text { positive(a) } \\
48\end{array}$ & $\begin{array}{l}\text { False positive } \\
\text { (b) } \\
4\end{array}$ & $\begin{array}{c}a+b \\
91\end{array}$ \\
\hline Negative & $\begin{array}{c}\text { False } \\
\text { negative (c) } \\
5\end{array}$ & $\begin{array}{l}\text { True negative } \\
\text { (d) } \\
43\end{array}$ & $\begin{array}{c}c+d \\
9\end{array}$ \\
\hline Total & $\begin{array}{c}a+c \\
53\end{array}$ & $\begin{array}{c}b+d \\
47\end{array}$ & 100 \\
\hline
\end{tabular}

Table-IV. Diagnostic accuracy of CT perfusion using PEI in detecting high grade pancreatic ductal adenocarcinoma keeping histopathology as gold standard $(n=100)$

Sensitivity $\quad=a /(a+c) \times 100=90.56 \%$

Specificity $\quad=d /(d+b) \times 100=91.49 \%$

Positive predictive value $=a /(a+b) \times 100=92.31 \%$ Negative predictive value $=d /(d+c) \times 100=89.58 \%$ Accuracy rate $\quad=a+d /(a+d+b+c) \times 100=91 \%$

The data was stratified for age and gender to control the effect modifiers. (Table-V and VI).

\begin{tabular}{|c|c|c|c|}
\hline \multirow[b]{2}{*}{ P-CT } & \multicolumn{2}{|c|}{ Histopathology } & \multirow[b]{2}{*}{ P-Value } \\
\hline & $\begin{array}{c}\text { Pancreatic } \\
\text { Carcinoma } \\
\text { (Positive) }\end{array}$ & $\begin{array}{l}\text { Pancreatic } \\
\text { Carcinoma } \\
\text { (Negative) }\end{array}$ & \\
\hline Positive & $\begin{array}{c}\text { True } \\
\text { positive(a) } \\
4\end{array}$ & $\begin{array}{l}\text { False positive } \\
\text { (b) } \\
0\end{array}$ & \multirow{2}{*}{0.00} \\
\hline Negative & $\begin{array}{c}\text { False } \\
\text { negative (c) } \\
1\end{array}$ & $\begin{array}{l}\text { True negative } \\
\text { (d) } \\
7\end{array}$ & \\
\hline
\end{tabular}


Specificity $\quad=d /(d+b) \times 100=100 \%$

Positive predictive value $=a /(a+b) \times 100=100 \%$ Negative predictive value $=d /(d+c) \times 100=87.5 \%$

Accuracy rate $=a+d /(a+d+b+c) \times 100=91.67 \%$

\begin{tabular}{|c|c|c|c|}
\hline \multirow{2}{*}{ P-CT } & \multicolumn{2}{|c|}{ Histopathology } & \\
& $\begin{array}{c}\text { Pancreatic } \\
\text { Carcinoma } \\
\text { (Positive) }\end{array}$ & $\begin{array}{c}\text { Pancreatic } \\
\text { Carcinoma } \\
\text { (Negative) }\end{array}$ & P-Value \\
\hline \multirow{3}{*}{ Positive } & $\begin{array}{c}\text { True } \\
\text { positive(a) } \\
44\end{array}$ & $\begin{array}{c}\text { False } \\
\text { positive (b) } \\
4\end{array}$ & \\
\hline & False & True & 0.00 \\
\hline \multirow{2}{*}{ Negative } & negative(c) & negative (d) & \\
& 4 & 36 & \\
\hline
\end{tabular}

Table-V. Stratification for to age $30-45$ years

Sensitivity $\quad=a /(a+c) \times 100=91.67 \%$

Specificity $\quad=d /(d+b) \times 100=90 \%$

Positive predictive value $=a /(a+b) \times 100=91.67 \%$

Negative predictive value $=d /(d+c) \times 100=90 \%$

Accuracy rate $=a+d /(a+d+b+c) \times 100=90.91 \%$

\begin{tabular}{|c|c|c|c|}
\hline \multirow[b]{2}{*}{ P-CT } & \multicolumn{2}{|c|}{ Histopathology } & \multirow[b]{2}{*}{ P-Value } \\
\hline & $\begin{array}{c}\text { Pancreatic } \\
\text { Carcinoma } \\
\text { (Positive) }\end{array}$ & $\begin{array}{c}\text { Pancreatic } \\
\text { Carcinoma } \\
\text { (Negative) }\end{array}$ & \\
\hline Positive & $\begin{array}{c}\text { True } \\
\text { positive(a) } \\
35\end{array}$ & $\begin{array}{c}\text { False } \\
\text { positive (b) } \\
2\end{array}$ & \multirow{2}{*}{0.00} \\
\hline Negative & $\begin{array}{c}\text { False } \\
\text { negative (c) } \\
2\end{array}$ & $\begin{array}{c}\text { True } \\
\text { negative }(d) \\
18\end{array}$ & \\
\hline
\end{tabular}

Table-VI. Stratification for to gender Male

$\begin{array}{ll}\text { Sensitivity } & =a /(a+c) \times 100=94.59 \% \\ \text { Specificity } & =d /(d+b) \times 100=90 \%\end{array}$

Positive predictive value $=a /(a+b) \times 100=94.59 \%$

Negative predictive value $=d /(d+c) \times 100=90 \%$

Accuracy rate $=a+d /(a+d+b+c) \times 100=92.98 \%$

\section{Female}

\begin{tabular}{|c|c|c|c|}
\hline \multirow{2}{*}{ P-CT } & \multicolumn{2}{|c|}{ Histopathology } & \multirow{2}{*}{ Pancreatic } \\
& $\begin{array}{c}\text { Carcinoma } \\
\text { (Positive) }\end{array}$ & $\begin{array}{c}\text { Pancreatic } \\
\text { Carcinoma } \\
\text { (Negative) }\end{array}$ & \\
\hline \multirow{3}{*}{ Positive } & True & False & \\
& positive(a) & positive (b) & \\
\hline & 35 & 2 & \multirow{2}{*}{0.00} \\
\hline \multirow{2}{*}{ Negative } & False & True & \\
& negative(c) & negative (d) & \\
& 2 & 18 & \\
\hline
\end{tabular}

Sensitivity

Specificity $=\mathrm{a} /(\mathrm{a}+\mathrm{c}) \times 100=81.25 \%$ $=d /(d+b) \times 100=92.59 \%$

Positive predictive value $=a /(a+b) \times 100=86.67 \%$ Negative predictive value $=d /(d+c) \times 100=89.29 \%$ Accuracy rate $=a+d /(a+d+b+c) \times 100=88.37 \%$

\section{DISCUSSION}

Pancreatic ductal carcinoma is one of the most prevalent cancers involving pancreatic tissue with a poor prognosis and significant mortality. The early and accurate cellular diagnosis and staging with grading of this type of pancreatic cancer is required in order to minimize un-necessary surgical procedures. ${ }^{3}$

Perfusion CT (PCT) has recently aroused the interest of many researchers and further studies have been designed thereafter. ${ }^{4}$ It provides a noninvasive method to evaluate the variables that provide insight into angiogenesis. ${ }^{6}$ This study was thus being carried out that how accurately CT perfusion can detect high grade pancreatic ductal adenocarcinoma by noninvasive method and by accurate characterization of histologic grade this study may help doctors to opt for targeted treatment and early deaths due to unnecessary surgery can be avoided.

In this study, out of 100 cases, $36 \%(n=26)$ were between $30-45$ years of age while $74 \%(n=74)$ were between $46-60$ years age, mean + Standard Deviation calculated as $50.15+6.60$ years, $57 \%(n=57)$ were male while $43 \%(n=43)$ were females. The diagnostic accuracy of CT perfusion using PEI in detecting high grade pancreatic ductal adenocarcinoma keeping histopathology as gold standard was recorded as $90.59 \%$, 91.49\%, 92.31\%, 89.58\% and $91 \%$ for sensitivity, specificity, positive predictive value, negative predictive value and accuracy rate.

We compared with previous studies showing that prevalence of high grade ductal adenocarcinoma is $62.5 \%$ considering PEI perfusion CT identified high grade lesions with $65 \%$ sensitivity \& $92 \%$ specificity. $^{3}$ Sensitivity and specificity for endoscopic ultrasound guided fine needle cytology is $88.6 \%$ and $99.3 \%$ respectively. ${ }^{8}$ These findings correspond to our results. 
According to D'Onofrio $M$ and others ${ }^{3}$ using ROC curves, the cut-off values for PEI and BV were taken for the identification of various lesions tumors were have been. They concluded that PEI perfusion parameter with cut-off $17.8 \mathrm{HU}$ can point out various adenocarcinomas with a total accuracy of about $75 \%$. Similarly, BV perfusion parameter with cut-off $14.8 \mathrm{ml} / 100 \mathrm{~g}$ pointed out various adenocarcinomas with a total accuracy of $78.1 \%$. Using the perfusion parameters of $\mathrm{PEI}$ and $\mathrm{BV}$, pancreatic ductal high-grade adenocarcinomas can be identified to sensitivity and specificity of $60 \%$ and $100 \%$ along with PPV $100 \%$, a NPV of $60 \%$ and accuracy of $75 \%$. In our study, we used PEI value of $17.8 \mathrm{HU}$ as cut-off for diagnosis of high grade pancreatic adenocarcinoma and recorded a higher accuracy rate, we are of the that some other trials are required to validate our results, moreover, some other studies should be done to compare different cut-off values like 17.8 $\mathrm{HU}$ and $14.8 \mathrm{HU}$ which may enable us for more conclusive results.

\section{CONCLUSION}

We concluded that diagnostic accuracy of CT perfusion using $\mathrm{PEI}$ is higher in detection of high grade pancreatic ductal adenocarcinoma keeping histopathology as gold standard.

\section{CONFLICT OF INTEREST}

The authors of this article declare no conflict of interest

Copyright $\odot 02$ April, 2019.

\section{REFERENCES}

1. Klauss M, Stiller W, Pahn G, Fritz F, Keiser M, Werner $J$, et al. Dual energy perfusion CT of pancreatic adenocarcinoma. Eur J of Radiol. 2013; 82:208-14.

2. Wolfgang CL, Herman JM, Laheru DA, Klein AP, Erdek MA, Fishman EK, et al. Recent progress in pancreatic cancer CA cancer J clin. 2013; 63:318-48.

3. D'Onofrio M, Gallotti A, MantoVani W, Crosari S, Manfrin E, Falconi M, et al. Perfusion CT can predict tumoral grading of pancreatic adenocarcinoma. Eur $\mathrm{J}$ Radiol 2013; 82:227-33.

4. Sousa JPLBA, Bekhor D, Filho CFS, Bretas EAS, D`Ippolito G. Abdominal perfusion computed tomography: Clinical applications, principles and technique RadiolBras 2012; 45:39-45.

5. Xie Q, Wu J, Tang $Y$, Dou $Y$, Hao S, Feja Xu, et al. Whole organ CT perfusion of pancreas: Impact of iterative reconstruction on image quality, perfusion parameters and radiation dose in 256 slice CT preliminary findings PLoS One. 2013; 8:e80468

6. Zakaria $\mathrm{Y}$, Kafadar S, Kafadar H. Role of advanced md CT applications in evaluation and pre-operative assessment of pancreatic tumors. Aust $\mathrm{J}$ Cancer Clin Res 2014; 1:1011.

7. Delure L, Blanckeart P, Mertens D, Merbeeck S, Ceelan $W$, Duyik $P$ et al. Tissue perfusion in pathologies of pancreas: Assessment using 128-slice computed tomography Abdom Imaging 2012; 37:595-601.

8. Hebert-Magee S, Bae S, Varadarajulu S, Ramesh J, Frost AR, Eloubeidi MA, Eltoum IA. The presence of a cytopathologist increases the diagnostic accuracy of endoscopic ultrasound-guided fine needle aspiration cytology for pancreatic adenocarcinoma: a meta-analysis. Cytopathology. 2013 Jun;24(3):15971. 


\begin{tabular}{|c|c|c|c|}
\hline \multicolumn{4}{|c|}{ AUTHORSHIP AND CONTRIBUTION DECLARATION } \\
\hline Sr. \# & Author(s) Full Name & Contribution to the paper & Author(s) Signature \\
\hline 1 & Abdul Raouf & Data collection. & \\
\hline 2 & Adeela Abid Bukhari & Data collection, Data entry. & Adectosind \\
\hline 3 & Natasha Arshad & Data collection. & \\
\hline 4 & Muhammad Ahsan & Data analysis, Paper writing. & \\
\hline
\end{tabular}

